\title{
Desenvolvimento territorial sustentável: desafios sem fronteiras
}

\author{
Sustainable territorial development: challenges without borders \\ Développement territorial durable: enjeux sans frontières
}

Desarrollo territorial sostenible: retos sin fronteras

\author{
Vinicius Nobre Lages* \\ (vinicius.lages@sebrae.com.br)
}

Recebido em 1\%/06/2013; revisado e aprovado em 20/08/2013; aceito em 04/10/2013

\begin{abstract}
Resumo: Este trabalho foi adaptado a partir da apresentação do tema "Desenvolvimento territorial sustentável: desafios sem fronteiras", na ocasião do Seminário Internacional sobre Desenvolvimento Territorial Sustentável, ocorrido em agosto de 2013, na Fundação Universidade Dom Bosco de Campo Grande, MS. De caráter opinativo, este texto procura apresentar a missão institucional do Serviço Brasileiro de Apoio às Micro e Pequenas Empresas (SEBRAE), destacando de que forma tal missão se orienta na direção de contribuir para o desenvolvimento territorial sustentável, bem como busca solucionar os desafios inerentes ao processo de desenvolvimento nacional.

Palavras-chave: Desenvolvimento territorial sustentável. SEBRAE. Pequenos negócios.

Abstract: This work was adapted from the presentation of the theme "Sustainable territorial development: challenges without borders" on the occasion of the International Seminar on Sustainable Territorial Development, held in August 2013, at the Fundação Universidade Dom Bosco, Campo Grande, MS. Opinionated character, this text seeks to present the institutional mission of the Brazilian Service of Support for Micro and Small Enterprises (SEBRAE), highlighting how such a mission is geared towards contributing to sustainable territorial development, as well as seeking to solve the challenges inherent in the process of national development.

Key words: Sustainable territorial development. SEBRAE. Small business.

Resúmé: Ce document a été adapté à partir de la présentation du thème “Développement territorial durable: enjeux sans frontiers" à l'occasion du Séminaire international sur le développement territorial durable, qui s'est tenue en Août 2013 à la Fundação Universidade Dom Bosco, Campo Grande, MS. Caractère opiniâtre, ce texte cherche à présenter la mission institutionnelle du Service brésilien d'appui aux micro et petites entreprises (SEBRAE), soulignant combien une telle mission est axée sur la contribution au développement territorial durable, ainsi que chercher à résoudre le les défis inhérents au processus de développement national.

Mots-clés: le développement territorial durable. SEBRAE. Petite entreprise.

Resumen: Este trabajo es una adaptación de la presentación del tema “Desarrollo territorial sostenible: retos sin fronteras", en ocasión del Seminario Internacional sobre Desarrollo Territorial Sostenible, celebrado en agosto de 2013. De carácter opinativo, este texto busca presentar la misión institucional del Servicio Brasileño de Apoyo a las Micro y Pequeñas Empresas (SEBRAE), destacando como esa misión se orienta a contribuir para un desarrollo territorial sostenible, así como tratar de resolver los retos inherentes en el proceso de desarrollo nacional.

Palabras clave: desarrollo territorial sostenible. SEBRAE. Pequeñas empresas.
\end{abstract}

\section{Introdução}

Este texto circunscreve o tema "Desenvolvimento territorial sustentável: desafios sem fronteiras" apresentado no Seminário Internacional sobre Desenvolvimento Territorial Sustentável, ocorrido em agosto de 2013. Vale ressaltar que o presente trabalho expressa as opiniões pessoais do autor.

Tratamos de elaborar, de forma abreviada, o entendimento e a prática do Sistema Sebrae (Serviço Brasileiro de Apoio às Micro e Pequenas Empresas) em torno do tema. Reconhecemos, desde logo, tratar-se de desafio de dupla dimensão. Por um lado, refletir sobre a polissemia envolvendo esse trinô- mio que intitula o Seminário Internacional: desenvolvimento territorial sustentável. Por outro, articular os dois últimos conceitos que adjetivam o tipo de desenvolvimento que se pretende alcançar, ou ao menos, que serve de referencial ao Programa Erasmus Mundus. Tanto desenvolvimento quanto os qualificativos territorial e sustentável são objetos de ampla produção científica, cuja elucidação é apenas tangenciada pela abordagem presente no texto.

Nosso objetivo será, portanto, apresentar a pertinência do tema mencionado com a missão institucional do Sebrae, destacando de que forma a missão desempenhada por essa instituição se orienta na direção de

\footnotetext{
* Sebrae Nacional, Brasília, DF, Brasil.
} 
contribuir para o desenvolvimento territorial sustentável.

Ao fazer essa contextualização, pretendemos tanto apresentar a progressiva aproximação com a dimensão territorial do desenvolvimento, indicando as duas abordagens predominantemente territoriais que a instituição desenvolve. Concluímos com os principais desafios enfrentados por uma estratégia de desenvolvimento territorial sustentável, que considera o fim dos limites fronteiriços nacionais em seus nexos globais tanto materiais quanto imateriais.

\section{Desafios do desenvolvimento}

O Sebrae completou recentemente 40 anos de existência, tendo por missão o apoio ao desenvolvimento competitivo e sustentável dos pequenos negócios e fomento ao empreendedorismo, para fortalecer e economia nacional. Exerce, nesse sentido, um duplo papel, tanto fortalecendo e desenvolvendo as capacidades produtivas dos pequenos negócios em busca de maior competitividade e sustentabilidade, quanto de agência de desenvolvimento, atuando sobre o ambiente de negócios e sobre os fatores externos que afetam a competitividade e sustentabilidade dos pequenos negócios. Oferece cursos, consultorias, orientação empresarial, e por outro, articula parcerias, e também promove uma agenda de políticas públicas e age para que os pequenos negócios recebam um tratamento diferenciado, conforme determina a Constituição Federal de 1988.

Em um país de dimensões continentais ainda fortemente marcado por desigualdades e elevados índices de pobreza e miséria, uma instituição como o Sebrae se constitui como agente relevante para o enfrentamento dos desafios do desenvolvimento, sobretudo porque as micro e pequenas empresas compõem a maioria dos negócios existentes.

Há muito se reconhece a importância do papel dos pequenos negócios na economia nacional, tendo a Carta Magna de 1988 e sucessivos instrumentos legais assegurando um tratamento diferenciado a esse segmento.

Em toda América Latina e Caribe, os pequenos negócios compõem cerca de 60 milhões de empreendimentos que, apesar de sua importância econômica e social, ainda não foram devidamente integrados ao miolo da economia (mainstream economics). No entanto, em quase todo o continente existem políticas públicas focadas neste segmento, bem como instituições dedicadas ao seu apoio e desenvolvimento. Este é o caso do Brasil, que além de contar com o Sebrae, acaba de criar uma Secretaria Especial com status de Ministério, para apoio ao segmento. Esse tratamento diferenciado deriva da vontade política de se estabelecer ações visando a facilitação de acesso dos pequenos negócios a serviços empresariais e a políticas públicas que facilitem a melhoria de sua competitividade.

O tecido econômico nacional, majoritariamente composto por pequenos negócios, tem neste segmento um vetor importante de enfrentamento de problemas estruturais como pobreza, desigualdades, desemprego, baixa capacidade de inovação, desqualificação profissional e despreparo para abrir negócios.

O desenvolvimento dos pequenos negócios é cada vez mais parte da estratégia do país em sua transição para uma sociedade mais justa, próspera e inovadora. Sem um aumento significativo de produtividade deste segmento, a competitividade sistêmica da economia brasileira permanecerá limitada. Faz parte, portanto, da mesma equação de desigualdades sociais e regionais, o quadro de heterogeneidade dos padrões competitivos entre pequenos, médios e grandes empreendimentos. E essas dimensões se afetam mutuamente no que tange a capacidade de produzir bens e serviços, no que tange a capacidade de realização do potencial de desenvolvimento humano e econômico das distintas regiões do país e suas populações.

A dinâmica empreendedora da sociedade brasileira e o surgimento de pequenos negócios têm se constituído, na última década, em responsáveis pela maior parte da geração de postos de trabalho, sobretudo com carteira assinada. Os pequenos negócios formam quase a totalidade das empresas existentes no país (99\%) e estão espalhados em todo o território nacional, compondo a base do tecido econômico da maioria dos municípios brasileiros.

As diferenças de produtividade entre pequenos, médios e grandes negócios no Brasil é bastante acentuada, exigindo uma atenção especial do poder público e de insti- 
tuições como o Sebrae, que tem missão dedicada a esse segmento. Para reforçar o apoio aos pequenos negócios, o governo brasileiro criou recentemente uma secretaria especial de apoio às micro e pequenas empresas, com status de ministério.

Desenvolver significa eliminar entraves, dar e ampliar acesso, reduzir desigualdades, alcançar um estado de bem-estar, de felicidade e mesmo de condições materiais adequadas. Amartya Sen (1999), economista indiano, Prêmio Nobel de Economia de 1998, definia desenvolvimento enquanto expansão das liberdades, liberdade enquanto condição para o pleno desenvolvimento do potencial humano. A expansão da liberdade, segundo Amartya Sen, é o fim prioritário e, ao mesmo tempo, o meio principal do desenvolvimento. Desenvolvimento entendido como a remoção de um conjunto de restrições limitantes ao desenvolvimento humano, que reduzem ou impedem suas escolhas ou embotam seu potencial de desenvolvimento pleno. Liberdade, portanto, entendida em seu sentido ampliado, tanto política, social, quanto econômica.

Reconhecemos que os desafios do desenvolvimento, em especial a superação da pobreza, desigualdade e miséria, são desafios em que nem o Estado nem o mercado sozinhos resolvem. As falhas de ambos são amplamente registradas na vasta literatura e debate sobre o desenvolvimento desde o século XX. Somente com a universalização de acessos a direitos fundamentais e a serviços para uma inserção produtiva no mercado é que lograremos êxito em enfrentar os obstáculos que impedem os pequenos negócios e milhões de empreendedores potenciais de se desenvolverem.

Em um país com a grandeza territorial do Brasil, ainda marcado por significativas diferenças na capacidade de produzir conhecimento, renda, bens e serviços e mesmo de proporcionar condições dignas de vida a seus cidadãos, há muito tornou-se evidente que não poderíamos deixar a soluções desses problemas entregue ao acaso. Mesmo as condições mais precárias de vida, refletidas nos índices de pobreza urbana e rural, não foram obras do acaso, uma vez que refletem decisões de grupos hegemônicos de poder historicamente constituídos, que assim planejaram o abandono ou a marginalização de milhões de brasileiros. Neste contexto, Sachs (2012) ressalta que o desenvolvimento sustentável demanda essa visão de longo prazo, e que primeiramente deve entender a desigualdade abissal relacionada à qualidade de vida em cada nação.

Pensar o desenvolvimento nacional requer pensar nas escalas dos problemas enfrentados, em suas articulações com o território onde se inserem estes desafios, e em como se articulam com outras escalas do desenvolvimento nacional (micro, meso e macro).

Pensar o desenvolvimento territorial sustentável, na perspectiva dos pequenos negócios, passa, portanto, por pensar por além do público-alvo do Sistema Sebrae, os pequenos negócios atendidos e potenciais clientes. Implica, por outro lado, em entender como os pequenos negócios, foco primordial de nossa missão, inserirem-se nas dinâmicas de desenvolvimento dos territórios onde estão localizados, individualmente ou em distintas formas de associação.

\section{A dimensão local ou territorial do desenvolvimento dos pequenos negócios}

Pensar territorialmente significa pensar contextualmente. Pensar por além das empresas que apoiamos. O território emerge, por um lado, como unidade orientadora dos esforços coordenados, e por outro, em dimensão viva, dinâmica, a ser considerada numa estratégia de desenvolvimento.

Há tempos superamos a ilusão de que nossa missão se esgotaria na oferta de serviços aos pequenos negócios, atuando unicamente sobre as firmas, sobre as empresas, sem considerar os fatores externos da competitividade. Sem agir sobre as chamadas externalidades, os fatores estruturais ou sistêmicos da competitividade.

Pela mesma razão, entendemos que o tema da sustentabilidade deve ser tratado a partir de uma perspectiva ampliada, territorial, tal como proposto no Seminário Internacional sobre Desenvolvimento Territorial Sustentável, promovido pela Fundação Universidade Dom Bosco.

De forma mais explícita e construída através de distintas abordagens, há mais de uma década a dimensão territorial do desenvolvimento produtivo passou a ser uma 
dimensão chave das ações de apoio ao desenvolvimento de pequenos negócios.

Desenvolvimento local, desenvolvimento local integrado, arranjos produtivos locais, cadeias produtivas e suas dimensões territoriais, desafios da sustentabilidade sobre os territórios onde atuamos, localização de grandes investimentos, localização de elos dos encadeamentos produtivos onde se inserem os pequenos negócios que apoiamos, entre outros, são conceitos, princípios e ações que o Sebrae toma por base.

Com efeito, o Sistema Sebrae, a partir do entendimento da atuação das micro e pequenas empresas em dados territórios, busca compreender quais são os nexos desses territórios com o mundo, a saber:

- nexos materiais - insumos, produtos primários, elos das cadeias de valor, logística, infraestrutura e pessoas/migrações;

- nexos simbólicos - imagem, reputação, marcas, ícones, conhecimento, história, entre outros.

Um dos desafios do Sistema Sebrae reside no questionamento do que seria ampliar esses nexos, as conexões sustentáveis, como atrair mais pessoas, instituições e empresas, para gerar, por sua vez, uma grande rede de conhecimento e cooperação.

A competitividade de nossas empresas está intimamente ligada ao que fazemos com o território ou no território onde elas existem, onde existimos. Essa relação de interdependência, antes de ser um desafio, antes de ser uma barreira, pelas restrições de uso que podem impor, é uma grande oportunidade que pode efetivamente reposicionar o Brasil e seus territórios no contexto internacional. Quanto mais cedo tenhamos consciência disso, quanto mais cedo agirmos para integrar nossas ações de competitividade e de sustentabilidade dos territórios, mais cedo colheremos os frutos desse outro desenvolvimento que é possível.

Se antes a noção de território associavase unicamente à ideia de poder, soberania, proteção, fronteiras herméticas, limites, independência, hoje representa fronteiras fluidas, porosas, conexões, nexos, inovação aberta, aprendizagens, colaboração, interdependência, cooperação, integração.

Quanto menor e mais isolada for uma empresa ou um dado território, mais será necessário criar conexões e contar com agen- tes facilitadores dessas mesmas conexões. É neste contexto que atuamos nas frentes de cooperação internacional.

Vale destacar que os territórios passaram pouco a pouco a assumir uma dimensão por além do simples lócus da produção, do sustentáculo físico, como também um conjunto de informações relevantes e estratégicas para se pensar o desenvolvimento dos pequenos negócios.

As externalidades, as especificidades presentes, positivas e negativas, nos permitiu entender que a dimensão da pequena escala dos pequenos negócios isoladamente poderia ser repensada a partir das aglomerações produtivas, dos arranjos, dos grupos de empresas, das redes de fornecedores, das associações de produtores, de um conjunto de empresas participando de um dado encadeamento produtivo. Outra escala para os pequenos negócios é possível a partir dessas ações integradas entre eles.

A partir de uma análise territorial foi possível ampliar também o entendimento sobre logística integrada, reconhecer os ativos intangíveis do patrimônio imaterial que nos permitiram construir marcas territoriais, indicações geográficas. Já não falamos mais de café do Brasil, mas de cafés do Brasil e mesmo no estado de Minas Gerais, responsável por $52 \%$ da produção nacional, já reconhecemos essa diversidade de variedades que expressam distintos sabores e aromas, agregando valor ao produto dos pequenos negócios como forma de enfrentar as commodities.

A incorporação da dimensão territorial do desenvolvimento permite definir estratégias de rastreabilidade para atender a demandas de um mercado e de consumidores cada vez mais exigentes sobre informações de como são produzidos bens e serviços oriundos de um dado território. Na era do tempo real da internet e das redes sociais, da geolocaliação, dos aplicativos on line, já não é mais possível produzir de forma insustentável sem que rapidamente se saiba através das redes sociais. Reputações são construídas e destruídas de forma muito veloz, tornando cada vez mais os nexos materiais e imateriais entre os produtores e seu território, um continuum que os franceses chamam de "território-empresa".

Nos territórios podemos entender e contribuir para acelerar processos de inovação a 
partir de aprendizagens e propostas de valor compartilhadas, em especial nos arranjos produtivos e grupos de empresas inseridas em projetos comuns. Aprender a inovar juntos, aprender a inovar com outros territórios, onde quer que estejam, são desafios de um processo de desenvolvimento sem fronteiras.

Por ser a célula básica das ações políticas, foi também nos territórios que descobrimos a importância da governança, dos processos de coordenação entre atores públicos e privados e entre eles mesmos. Trabalhamos o chamado capital social, as relações de cooperação e "coopetição" entre agentes produtivos e partes interessadas de um dado projeto (stakeholders).

Sobre a sustentabilidade, ainda que reconheçamos todas as dimensões como relevantes (sobretudo a dimensão social, econômica e ambiental), fizemos uma escolha mais pragmática em um primeiro momento, optando pela eficiência energética e a redução de resíduos como elementos mais próximos da gestão ambiental pelos pequenos negócios.

No entanto, sabemos que muito mais está em jogo, em especial a gestão dos recursos hídricos, que será cada vez mais um fator chave da competitividade. A gestão das bacias hidrográficas é hoje um desafio fundamental no desenvolvimento econômico de países africanos, da Índia, da Austrália. Quanto mais testemunhamos câmbios climáticos importantes, mais este tema sobe na lista de prioridades.

O desenvolvimento dos pequenos negócios tem evidentemente tudo a ver com desenvolvimento territorial sustentável, na medida em que fatores chave da competitividade estão por vezes muito mais relacionados à externalidades, a fatores do ambiente de negócios, do entorno, do que a fatores internos aos pequenos negócios. Se para as grandes empresas, para o agronegócio, que no Brasil já assumem hoje posição de liderança global, a competitividade está hoje severamente limitada pelos fatos externos, como a logística, como não arguir que os pequenos também dependem cada vez mais desses fatores.

O Sistema Sebrae trabalha basicamente com duas abordagens territoriais predominantes:

- Uma vinculada aos territórios de menor densidade empresarial, de menor índice de desenvolvimento humano, e sobre estes territórios desenvolvemos um conjunto de projetos voltados ao aproveitamento dos investimentos, ao despertar da vocação empresarial e empreendedora e da inclusão produtiva;

- Outra voltada para territórios de maior densidade empresarial, onde se concentram os investimentos, a maioria das empresas e grandes oportunidades de negócios, das cadeias de valor global. Nestss territórios apoiamos grupos de empresas, arranjos produtivos e encadeamentos empresariais entre pequenas, médias e grandes empresas. É aí que temos uma abordagem mais setorial, e mesmo com foco em certos segmentos de alguns setores. Focamos também nos territórios onde ocorrem os grandes investimentos em infraestrutura e nas oportunidades derivadas dos grandes eventos (Copa do Mundo de Futebol da FIFA/2014 e os Jogos Olímpicos e Paraolímpicos de Verão/2016, entre outros).

Essas duas abordagens, no entanto, estão sendo objeto de constante aprimoramento e fertilização cruzada. Ou seja, as abordagens setoriais e territoriais tendem a abordar desafios que consideram tanto as dimensões específicas de certos territórios, como também as dimensões setoriais. Por outro lado, o desenvolvimento territorial amplia-se pouco a pouco na direção de outras tipologias de territórios, incluindo desafios específicos de biomas, da faixa de fronteira e de territórios com desafios específicos, tais como os municípios de áreas de influências de grandes investimentos (em mineração e em infraestrutura, por exemplo), que tanto impactam quanto alteram substancialmente as variáveis do desenvolvimento local e abrem enormes oportunidades para os pequenos negócios. E em todos esses territórios, os limites de uma estratégia de desenvolvimento não se encerram numa linha abstrata da geografia clássica dos espaços de um dado projeto. O desenvolvimento, sobretudo o desenvolvimento territorial sustentável, deve ser pensado como sendo um processo sem fronteiras, que requer atenção aos distintos nexos já mencionados, nas escalas local, estadual, regional, nacional e global. 


\section{Considerações finais}

Considerando o que foi exposto, podemos afirmar que o Sistema Sebrae, ao estabelecer estratégias de abordagens de atendimento empresarial, está construindo um mosaico dos territórios brasileiros onde estão presentes os pequenos negócios e onde as oportunidades para seu desenvolvimento se apresentam. Além disso, está apoiando a inclusão produtiva de milhões de brasileiros através do apoio aos empreendedorismo e aos pequenos negócios em regiões menos integradas ao desenvolvimento nacional.

Em um país com a grandeza territorial do Brasil esse esforço de integração das diferentes escalas da estratégias de desenvolvimento deve ser um pressuposto permanente das estratégias de desenvolvimento nacional.

Ainda que nossa missão seja a de apoiar os pequenos negócios brasileiros, reconhecemos que não devemos ignorar as dimensões internacionais do processo de desenvolvimento, bem como a importância de ampliar nossos nexos internacionais através de acordos de cooperação. Tanto a cooperação recebida quanto prestada devem ser instrumentos orgânicos de uma estratégica que amplia as oportunidades de aprendizagem de apoio aos pequenos negócios.

O Brasil é um país de dimensões continentais que faz fronteira diretamente com dez países.

Consideramos o entendimento de que não podemos apenas nos restringir ao território nacional como uma das recentes inovações institucionais do Sistema Sebrae. Isto é ainda mais evidente no contexto fronteiriço ou em territórios com fortes nexos com processos de internacionalização. Na medida em que entendemos o desenvolvimento dos pequenos negócios em cadeias de valor, percebemos que as oportunidades de negócios ultrapassam os limites estritos do mandato que temos para atuar no território nacional, estendendo essa atuação para onde as cadeias de valor envolvem pequenos negócios brasileiros.

É natural, portanto, que o desenvolvimento territorial sustentável, ao menos na faixa de fronteira com os 11 estados brasileiros, que esses limites sejam mais fluídos e sigam os processos reais da economia, como exemplificado no Projeto Mato Grosso do Sul Sem Fronteiras, também apresentado neste número especial desta revista.

São, portanto, esses desafios e oportunidades que nos movem a construir estratégias de cooperação internacional com objetivos de gerar fluxos de conhecimento e aprendizagens com instituições congêneres e afins em outros países, mas, sobretudo, construir pontes, estreitar relações com vistas ao fortalecimento das relações empresariais com nossos clientes.

\section{Referências}

SACHS, Ignacy. De volta à mão invisível: os desafios da Segunda Cúpula da Terra no Rio de Janeiro. Estudos Avançados [on line], São Paulo, v. 26, p. 5-20, 2012. Disponível em: <http://www.scielo.br/scielo. php?script=sci_pdf\&pid=S010340142012000100002\&l ng=en\&nri\&tlng=pt>. Acesso em: 09 set. 2013.

SEN, Amartya. Development as Freedom. Oxford University Press, Oxford, 1999. 